\title{
Discrete Choice Analysis of Travel Behaviour
}

\author{
Michal Šimeček ${ }^{a}$ \\ ${ }^{a}$ CDV - Transport Research Centre, Brno, Czech republic
}

\begin{abstract}
The article briefly presents discrete choice analysis as a method to investigate human judgment from an econometric perspective. It focuses on an analysis of the results of a survey on passengers in Slovakia that took place in 2014. The passenger survey addressed 811 respondents who made decisions regarding the choice of transport mode between car, train and bus in stated preference design. In addition, the results of the survey included the values of time in public transportation and for car users. The value of time for car users $(3.86 \mathrm{EUR} / \mathrm{h})$ is greater than value of time for public transport passengers (2.98 EUR/h for bus and $2.46 \mathrm{EUR} / \mathrm{h}$ for rail passengers). The value of time for leisure trips is greater than value of time for work commuting or other purposes.
\end{abstract}

KEYWORDS: Discrete choice analysis; stated preference survey; value of time; transport modelling; transport planning

\section{INTRODUCTION}

Discrete choice analysis (DCA) or preference analysis is an approach very popular in marketing, transport and many other fields. It helps researchers to understand how and why people make decisions concerning commercial products or public services, such as transport. Regarding the fast development of the society, the detailed knowledge of the market becomes crucial. The preference analysis helps to understand how and why a consumer makes decisions to choose a product.

DCA is based on the microeconomic theory of maximization of benefits, which reads that every human or organisation makes decisions so that they would maximize benefits for themselves. Daniel McFadden developed a theory and methods of statistical analyses of discrete choice, and with the use of these analyses he managed to quantify (e.g. enumerate in money) benefits from a product, e.g. public in- vestment (Ben-Akiva \& Lerman, 1985; Pearce et al., 2002; JASPERS, 2014).

Based on the concept of DCA, a person makes a choice among all mutually exclusive alternatives that are possible. The final decision always means choosing one of these alternatives. Therefore, it makes not much sense to ask people whether they would rather go to work (or how often) by car or by public transport and use, for example, a five-point scale. Such questioning method seems to be ineffective to help understand human decisions. Regarding the analysis and prediction of choices, it is more suitable to let respondents choose between different alternatives and then statistically process the results together.

Public carriers (e.g. city, railway and bus) as well as transport infrastructure operators try to combine their services so that they can satisfy and attract as many potential customers as possible. However, each service improvement or a new service introduction requires certain costs which customer will pay in the end. Discrete choice analysis (DCA) allows to monetarize (financially enumerate) the value of these services for customers. Thus, the carrier will know, based on the survey, how much passengers are willing to pay for certain services or their improvements. This type of a survey needs to be made in the form of stated preferences, when respondent chooses among hypothetical transport alternatives, and where so far unimplemented services may be integrated together with their attributes. Therefore, willingness to pay for services can answer questions for a public carrier, such as:

\section{What is the value of time for public transport customers?}

How many customers are willing to pay for a place in a public transport vehicle?

How many customers are willing to pay for additional services in public transport?

A feasibility study on the modernization of the railway corridor between towns of Žilina, Košice and Čierna n. T. in Slovakia was carried out in 2014. In ad- 
dition, this study included stated preference surveys for passengers and freight forwarders. The primary purpose of these surveys was to set parameters of the mode choice in the transport model of the Slovak Republic (Šimeček \& Dufek, 2016).

\section{STATED PREFERENCE SURVEY IN SLOVAKIA}

In Slovakia, a survey was made in 2014 assessing the usefulness of improvements of a rail connection as well as the introduction of new services on railways, such as Wi-Fi and air conditioning in vehicles (Šimeček \& Dufek, 2016). The survey was made with 811 respondents from the whole Slovakia.

Table 1. Respondent characteristics.

\begin{tabular}{lll}
\hline Respondents by groups & $\mathrm{n}$ & $\%$ \\
\hline Sociodemography & 91 & 11 \\
student & 450 & 55 \\
employed & 270 & 33 \\
$\quad$ unemployed / inactive & & \\
\hline Car availability & 597 & 74 \\
car available & 214 & 26 \\
car unavailable & & \\
\hline Trip purpose & 156 & 19 \\
work & 38 & 5 \\
school & 257 & 32 \\
leisure & 360 & 44 \\
other & 811 & 100 \\
\hline Total & &
\end{tabular}

The survey consisted of a short socio-demographic survey and an SP survey, when a respondent was assigned with a scenario on the trip from home with a certain purpose (work, education, leisure activity, and another purpose) for a certain distance (20,60, $100 \mathrm{~km})$. The respondent was to make four decisions among three alternative transport modes (train, bus, and car). In case the respondent has no car available, this alternative was not applicable. The respondents were asked to choose the most preferred alternative from the presented scenarios.

Just a single individual attribute was used, namely the reduced fare on public transport (bus or rail) $\beta$ Disc.

The alternatives "train" and "bus" had the same attributes:

- Travel time from home to a bus or train stop BAccT

- Travel time by particular mode - $\beta$ IVTBus, BIVTRail

- Travel time from a bus or train to destination (5, 10 or 15 minutes) - $\beta$ EgrT

- Travel cost - $\beta$ Cost

- Occupancy rate (certainty of finding a seat or a risk of standing) - $\beta$ ORail, $\beta$ OBus

- Modern design of vehicle (old vehicle or a modern vehicle with air-conditioning and Wi-Fi) - $\beta$ New

The alternative "car" only had two attributes:

- Travel time by particular mode - $\beta$ IVTCar

- Price for fuel and parking - $\beta$ Cost

Imagine traveling to work $20 \mathrm{~km}$ away from your home. Here are different ways to take the trip.

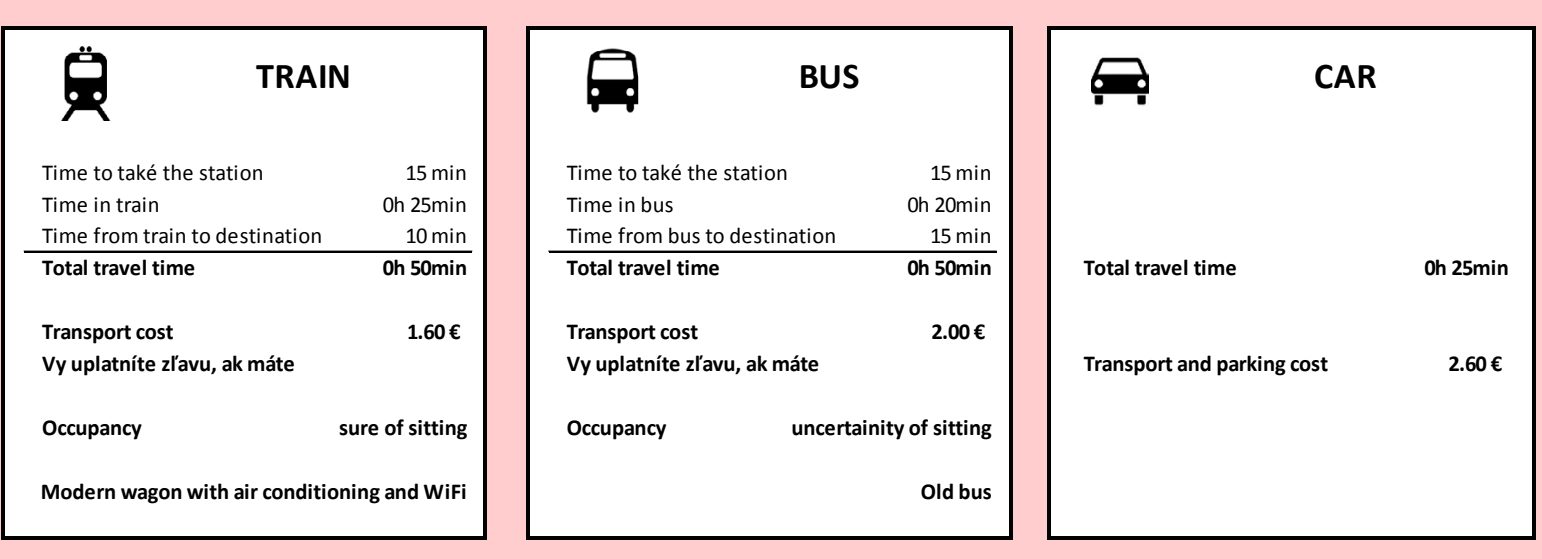




\section{MULTINOMIAL MODEL AND VALUE OF TIME}

Random utility multinomial logit model is developed by Daniel McFadden (Dubin \& McFadden, 1984; Bierlaire, 1998). In this model, the utility of each alternative $a$ and individual $i$ is given by

$$
U_{a}^{i}=V_{a}^{i}+\varepsilon_{a}^{i},
$$

where $\varepsilon_{a}^{i}$ is a random component and $V_{a}^{i}$ is the deterministic part of the utility given as linear combination of attributes of the alternative and its parameters. The probability that individual $i$ chooses an alternative $a$ from $M$ possible alternatives is

$$
p_{a}^{i}=\frac{e^{U_{a}^{i}}}{\sum_{n=1}^{M} e^{U_{n}^{i}}} .
$$

Value of time is defined as a financial amount that respondents are willing to pay for reducing travel time by one hour. Value of time can be obtained from the estimated model parameters as a fraction of the estimated travel time parameter and the estimated travel cost parameter. If the travel time is defined in minutes, the equation of value of time is as follows.

$$
\mathrm{VoT}=\frac{\beta_{t t}}{\beta_{\text {cost }}} \cdot 60
$$

To determine the value of time in different transport modes it is better to use in-vehicle-time, if available. Value of time is locally dependent and depends on the travel mode as well as on the purpose of the journey (Ben-Akiva \& Lerman, 1985; Henscher et al., 2005).

\section{RESULTS}

A common model was estimated for all data and then for different purposes separately (work commuting, leisure time, other purposes). The common model is shown in Table 2.

\section{Table 2. Common model estimation}

\begin{tabular}{lllll}
\hline \multicolumn{4}{l}{ Model evaluation } \\
\hline Parameters & 12 & & & \\
Rho $^{2}$ (adj.) & 0.314 & & & \\
\hline Term & Estimate & Rob. std err & Rob.t-test & $\mathrm{p}$ \\
\hline BusASC & 0.460 & 0.092 & 4.990 & 0.000 \\
CarASC & 2.840 & 0.152 & 18.710 & 0.000
\end{tabular}

\begin{tabular}{lllll}
$\beta$ Cost & -0.342 & 0.023 & -15.100 & 0.000 \\
$\beta$ IVTBus & -0.017 & 0.002 & -10.510 & 0.000 \\
$\beta$ IVTCar & -0.022 & 0.002 & -13.110 & 0.000 \\
$\beta$ IVTRail & -0.014 & 0.002 & -8.570 & 0.000 \\
$\beta$ AccT & -0.028 & 0.004 & -6.550 & 0.000 \\
$\beta$ EgrT & -0.017 & 0.007 & -2.520 & 0.010 \\
$\beta$ OBus & 0.636 & 0.072 & 8.860 & 0.000 \\
$\beta$ ORail & 0.607 & 0.079 & 7.680 & 0.000 \\
$\beta$ Disc & 1.260 & 0.095 & 13.210 & 0.000 \\
$\beta$ New & 0.337 & 0.052 & 6.540 & 0.000 \\
\hline
\end{tabular}

There are constants for car and bus travel modes (CarASC, BusASC) in the model, the constant for rail is set to zero. Models for different purposes (work/ school, leisure, other) were also estimated to allow different values of time to be set for these purposes.

Estimated parameters can be evaluated in the same way as the travel time parameter. A common model (see table 3) was used for these valuations.

\section{Table 3. Valuation of parameters from common model}

\begin{tabular}{ll}
\hline Name & Value and unit \\
\hline BusASC & $-1.35 \mathrm{EUR}$ \\
CarASC & $-8.30 \mathrm{EUR}$ \\
Access time & $4.91 \mathrm{EUR} / \mathrm{h}$ \\
Egress time & $2.98 \mathrm{EUR} / \mathrm{h}$ \\
In vehicle time - Bus & $2.98 \mathrm{EUR} / \mathrm{h}$ \\
In vehicle time - Car & $3.86 \mathrm{EUR} / \mathrm{h}$ \\
In vehicle time - Rail & $2.46 \mathrm{EUR} / \mathrm{h}$ \\
Bus occupancy & $-1.86 \mathrm{EUR}$ \\
Rail occupancy & $-1.77 \mathrm{EUR}$ \\
Discount ownership & $-3.68 \mathrm{EUR}$ \\
New public transport vehicle with air & $-0.99 \mathrm{EUR}$ \\
conditioning and Wi-Fi & \\
\hline
\end{tabular}

Car transport mode is generally more preferred than public transport in Slovakia. Respondents are willing to pay EUR 8.30 more for a trip by car than for a train trip and EUR 6.96 for a bus trip. The value of access time is relatively very high (4.91 EUR/h), i.e. higher than the value of time spent in a car. This means that unless people have very fast access to a railway station or an inter-city bus stop, they will easily opt for an individual transport mode which includes virtually no access time. The value of time for 
car users $(3.86 \mathrm{EUR} / \mathrm{h})$ is greater than value of time for public transport passengers $(2.98 \mathrm{EUR} / \mathrm{h}$ for bus and $2.46 \mathrm{EUR} / \mathrm{h}$ for rail passengers). Another very significant factor is comfort in public transport vehicles, which predominantly depends on vehicle occupancy rate and equipment. Let us try to monetarize this effect. People are willing to pay extra EUR 1.9 on a bus and EUR 1.77 on a train for the certainty to have a seat in a public transport vehicle. They are also willing to pay EUR 0.99 extra for travelling in a modern vehicle with Wi-Fi connection. Discounts to public transport fares (train or inter-city bus) correspond with an equivalent total bonus of EUR 3.68 as a reduced fare for public transport. The discount does not only include lower fare, but also easier use of public transport regarding seasonal fares. The customer does not need to buy tickets, which is a considerable improvement.

The estimated value of travel time for each travel mode and trip purpose in Slovakia is shown in Table bellow. The in-vehicle-time was used for the calculations.

Table 4. Value of time in Slovakia by travel mode and trip purpose [EUR/h]

\begin{tabular}{llll}
\hline Travel mode / purpose & Work & Leisure & Other \\
\hline Bus & 2.84 & 3.3 & 2.67 \\
Car & 4.12 & 3.59 & 3.86 \\
Rail & 2.21 & 3.02 & 2.03 \\
\hline
\end{tabular}

The value of time is grater for travelling by car than for public transport modes (rail and bus). The reason is that public transport is often used by less wealthy people and on the other hand travel time in public transport could be used for working or having a rest. The values of travel time are comparable with the results of a meta-analysis (Wardman, Chintakayala, de Jong, \& Ferrer, 2012) for Slovakia.

\section{CONCLUSION}

The value of time (Hensher et al., 2005) spent on the train amounted to $2.21 \mathrm{EUR} / \mathrm{h}$ for commuters to work and schools, i.e. these respondents are, on average, willing to pay EUR 2.21 more for one hour shorter travel time on the train. The value of time is lower than for a car (4.12 EUR/h), but comparable with the value of time for a bus (2.84 EUR/h). Regarding the trips for leisure activities, time values for trains, cars, and buses tend to approximate. The results are comparable with conclusions of a metastudy (Wardman et al., 2012) for Slovakia. Respondents at Slovakia are willing to pay EUR 0.99 extra for travelling in a modern vehicle with air conditioning and Wi-Fi connection.

Willingness to pay for customer services is significant information for the operators of these services but fails to answer the question how many new customers an operator can expect if certain services (service improvements) are introduced. The questions regarding changes in market share, i.e. elasticity, can be answered by incremental models (Martin \& McGuckin, 1998).

Acquiring data with the use of travel behaviour surveys has been a standard practice for several decades. Using stated preference surveys in transport has also become common since the 1990s. Several SP surveys have been performed in a number of states in the USA since the beginning of the $21^{\text {th }}$ century based on the introduction of high-speed railways (TEMS, 2008). These studies focused on the value of time, frequency of services, reliability, accessibility, and other properties. Similarly, they were used for evaluating public transport quality (incl. cleanliness and staff behaviour) of a connection to the campus of University of Calabria in Italy (Eboli \& Mazzulla, 2008).

The decision-making analysis has its place in studying travel behaviour. It helps to create the services in transport which their users consider valuable and are willing to pay for or which increase preferences for a particular transport mode. Transport mode choice analysis results are used in transport models and significantly influence their final properties and prediction abilities.

Acknowledgements: This article was produced with the financial support of the Ministry of Education, Youth and Sports within the programme of National Sustainability Programme I, project Transport R\&D Centre (LO1610), with the use research infrastructure acquired from the Operational Programme Research and Development for Innovations (CZ.1.05/2.1.00/03.0064).

\section{REFERENCES}

Ben-Akiva, M. E., \& Lerman, S. R. (1985). Discrete choice analysis: theory and application to travel demand (Vol. 9). Massachusetts: MIT press. 
Bierlaire, M. (1998). Discrete choice models. In M. Labbe, G. Laporte, K. Tanczos, \& P. Toint (Eds.), Operations research and decision aid methodologies in traffic and transportation management (pp. 203-227). Berlin: Springer.

De Jong, G. (2005). Value of freight travel-time savings. In D. A. Hensher \& K. J. Button (Eds.), Volume 1 - Handbook of transport modelling (pp. 553-564). Bingley: Emerald Group Publishing Limited.

Dubin, J. A., \& McFadden, D. L. (1984). An econometric analysis of residential electric appliance holdings and consumption. Econometrica: Journal of the Econometric Society, 345-362. DOI: $10.2307 / 1911493$

Eboli, L., \& Mazzulla, G. (2008). A stated preference experiment for measuring service quality in public transport. Transportation Planning and Technology, 31(5), 509-523. DOI: 10.1080/03081060802364471

Hensher, D. A., Rose, J. M., \& Greene, W. H. (2005). Applied choice analysis: a primer. Cambridge, UK: Cambridge University Press.

JASPERS Appraisal Guidance (Transport): The Use of Transport Models in Transport Planning and Project Appraisal. (2014). Retrieved from http://www.jaspersnetwork.org/plugins/servlet/documentRepository/ displayDocumentDetails?documentId $=222$

Martin, W. A., \& McGuckin, N. A. (1998). Travel estimation techniques for urban planning (No. 365). Washington, DC: National Academy Press.

Pearce, D., Özdemiroğlu, E., \& Britain, G. (2002). Economic valuation with stated preference techniques: summary guide. London: Department for Transport, Local Government and the Regions.

Šimeček, M., \& Dufek, J. (2016). A Freight Modal Shift Model for Slovakia. Transportation Research Procedia, 14, 2814-2819. DOI: 10.1016/j.trpro.2016.05.347

TEMS: High Speed Rail Feasibility Study Methodology Technical Report. (2008). Retrieved from http://rockymountainrail. org/documents/Methodology_Technical_Report_10_15_08_ $\underline{\text { final.pdf }}$

Wardman, M., Chintakayala, P., de Jong, G., \& Ferrer, D. (2012). European wide meta-analysis of values of travel time. ITS, University of Leeds, Paper prepared for EIB. Retrieved from http://www.significance.nl/papers/2012-European\%20 wide $\% 20$ meta-analysis $\% 20$ of $\% 20$ values $\% 20$ of $\% 20$ travel $\% 20$ time.pdf 